\title{
Challenges impacting functional recovery experienced by Mental Health Care Users with Major Depressive Disorder after a short-term admission to hospital
}

\author{
*Patricia A. de Witt, DOT(UP); MSc OT (Wits); PhD (Wits). https://orcid.org/0000-0003-3612-0920 \\ Sessional Adjunct Professor, Department of Occupational Therapy, School of Therapeutic Sciences, Faculty of Health Sciences University \\ of Witwatersrand, Johannesburg, South Africa.
}

Nadia Roestorff-Hambrock, B OT(UP); MSc OT(Wits). https://orcid.org/0000-0002-6340-0373

Occupational Therapist, Erbach, Germany. Postgraduate student, Department of Occupational Therapy, School of Therapeutic Sciences, Faculty of Health Sciences University of Witwatersrand, Johannesburg, South Africa.

Fasloen Adams, B OT(US); MSc OT(UCT); PhD(Wits). https://orcid.org/0000-000 I-6742-3727

Head of Department, Department of Occupational Therapy, School of Therapeutic Sciences, Faculty of Health Sciences University of Witwatersrand, Johannesburg, South Africa.

\section{Denise Franzsen, BSc OT (Wits); MSc OT (Wits); PhD (Wits); DTH(UP).} https://orcid.org/0000-000 I-8295-6329

Sessional Senior Lecturer, Department of Occupational Therapy, School of Therapeutic Sciences, Faculty of Health Sciences University of Witwatersrand, Johannesburg, South Africa.

Introduction: Major Depressive Disorder often has a chronic course. Mental Health Care Users (MHCUs) with this diagnosis report experiencing challenges with the transition to their home and in resuming their previous activities of daily living or their functional recovery after a short-term admission to hospital. This research aimed to explore these challenges which these MHCUs perceived had contributed to their re-admission within a six-month period.

Methods: A qualitative descriptive design was used to explore these challenges. Data were gathered through semi-structured interviews with eleven participants and analysed thematically.

Results: Data analysis generated two themes: 'Inability to fully benefit from the therapeutic programme' and 'Life was not what I expected it to be after discharge'. Participants reported struggling to participate fully in the occupational therapy programme during admission and with the abrupt transition from hospital to home. They reported challenges in implementing changes that they had committed to in hospital and a lack of support from significant others. The greatest challenge reported by participants was in the social participation category of occupation and their experiencing extreme loneliness and isolation after discharge.

Conclusion: The unresolved challenges experienced by participants during hospitalisation and after discharge were perceived to be detrimental to their functional recovery.

Keywords: major depressive disorder, mental health, re-admission, functional recovery

\section{INTRODUCTION}

Major Depressive Disorder (MDD) is a serious and recurrent disorder, which is predicted to be the leading cause of disability worldwide by 2030 '. More than $90 \%$ of people diagnosed with depression in South Africa reported "global role impairment" on the Sheehan Disability Scale, which indicated that they were unable to perform the daily activities related to their role responsibilities ${ }^{2}$.

Occupational impairments - with varying deficit levels in social participation - are commonly reported in mental health care users (MHCU's) with MDD. This results in poor engagement in daily occupations with resultant serious effects for the $\mathrm{MHCU}$, their families and communities ${ }^{3}$. The impairments related to engagement in occupations that accompany MDD should thus also be effectively addressed to improve outcomes of these MHCUs ${ }^{4}$.

Despite advances in the treatment of MDD the improvement of symptoms, impaired functioning and reduced quality of life can persist for a considerable period after discharge from hospital ${ }^{5}$. Lower levels of social functioning, amongst other factors, is reported to put MHCUs with MDD at risk of recurrence of the disorder ${ }^{6}$, indicating it's chronic nature. Although not each recurrence of the disorder requires further hospitalisation, for a substantial number of MHCUs with this disorder readmission to a mental health care unit is indicated ${ }^{7}$.

Specialised care is required for the treatment of persons diagnosed with MDD to be effective. In the South African private health care sector, admissions of MHCUs with MDD who rely on medical 
insurance are limited to three weeks' hospitalisation, regardless of their progress. Subsequently, many of these MHCUs are often discharged prematurely which can increase the risk of recurrence ${ }^{4}$. A two-year record review of MHCUs diagnosed with MDD at a private psychiatric hospital in South Africa where this research was conducted, revealed a readmission rate of $7.5 \%$ within a six-month period. The re-admitted MHCUs frequently reported poor dayto-day functioning and challenges in transitioning back into their home, work environment and society despite an intensive multidisciplinary intervention programme, including occupational therapy, during hospitalisation ${ }^{8}$. The exact nature of the challenges faced by the MHCU's were not known, making it difficult for occupational therapists to address the occupational performance difficulties that MHCUs faced when trying to re-establish their life post discharge.

\section{Literature review}

Major depressive disorder is estimated to affect 264 million people worldwide?. In South Africa, MDD is reported to have a lifetime prevalence of $9,8 \%$ and a 12 -month prevalence of $4,9 \%{ }^{10}$. This is consistent with a $9,75 \%$ lifetime prevalence rate, determined by the South African Stress and Health (SASH) study ${ }^{2}$, which suggested that one-in-ten South Africans will suffer a MDD episode in their lifetime ". The prevalence of depression in South African rural communities has been reported to be much higher, with a prevalence rate of $31,4 \%$ in the Eastern Cape ${ }^{12}$.

Amongst the symptoms of MDD, a depressed mood and loss of interest in pleasurable activities are the most indicative of the disorder. Other symptoms include loss of energy, changes in sleep pattern, decreased appetite, psychomotor retardation, feelings of worthlessness, recurrent suicidal thoughts and diminished concentration $^{13}$. The person's level of self-care, ability to sleep, participation in meaningful leisure activities as well as the ability to engage in interpersonal relationships may also be affected ${ }^{14}$. Emotional functioning, coping with domestic life and work as well as the ability to interact with others are experienced as particularly challenging ${ }^{15}$. In South Africa MDD has been associated with $27.2 \%$ of annual sick days, which lasts on average 18 days ${ }^{16}$. The severity of the symptoms and associated risk factors including suicide frequently result in MHCUs diagnosed with MDD being admitted to hospital.

Occupational therapy plays an integral part in the treatment of MHCU's diagnosed with MDD. The focus of intervention includes facilitating insight into the symptoms and behaviour related to the condition as well as the impact that MDD has on occupational performance and occupational roles ${ }^{17}$. Reducing stressors which often precipitate episodes of MDD, as well as developing coping skills are also priorities in occupational therapy, which aims at enabling MHCUs to engage in their occupations more effectively after discharge ${ }^{18}$.

Discharge from hospital, usually determined by the psychiatrist, is often based on the resolution of depressive symptoms with less importance placed on participation and the ability to carry out occupations, daily life activities or functional recovery after an MDD episode 4 . Thus, many MHCU's are hospitalised and discharged based on their response to medication ${ }^{19}$. Since functional recovery has been shown to lag behind the resolution of medical symptomology, especially during the index episode of $\mathrm{MDD}^{20}$, occupational dysfunction may constitute a greater risk of re-admission after early discharge ${ }^{4}$.

Functional recovery from mental illness, including MDD, relies on the active involvement of the MHCU in the everyday life in their own context while engaged in routine occupations and roles ${ }^{21}$. The Recovery Model recommended for MHCUs with MDD embraces a collaborative approach in which MHCUs are viewed as experts in their experiences of the disease ${ }^{22}$. In a study by Kelly et al. ${ }^{21}$ MHCUs reported barriers to engagement in daily occupations included a lack of support, reduced self-efficacy, low levels of self-worth, competence and skill. These barriers have been associated with continued stress and poor coping responses. The use of emotionbased and avoidance-based coping including limited self-efficacy, have been associated with the risk of relapse in MDD ${ }^{23}$. Relying on avoidance-coping instead of actively solving problems, has also been linked to lingering symptoms of depression.

Several theories and models implicate the causal role of the inability to deal with life stresses in recurrences of MDD after the index episode ${ }^{24}$. In particular the Stress-sensitisation model proposed by Post ${ }^{25}$, based on electrophysiological 'kindling', suggests that both the stressors precipitating a depressive episode and the depressive episode itself might result in biological changes that make a person more susceptible for subsequent depressive episodes ${ }^{26}$. Similarly, the Scar hypothesis of depression ${ }^{27}$ proposed that changes during an episode of depression, cause a 'scar', which makes a person increasingly susceptible to repetitive episodes. This was supported in a study by Mitchell et al. ${ }^{28}$ who found that subsequent episodes are triggered by milder stress which suggests that MHCUs become increasingly sensitive to stressors. The Stress-generation model proposed that the susceptibility to stress is partly influenced by the $\mathrm{MHCU}$ generating more stressful situation $\mathrm{s}^{29}$ as the product of behavioural and occupational dysfunction ${ }^{30}$.

The Integrated Model for Depression Relapse proposed by Backs-Dermott et al. ${ }^{31}$ further supports these theories. This model suggests that relapse risk was significantly linked to ongoing and unresolved stress that depletes a person's resources, especially if they experience ongoing occupational dysfunction and interpersonal difficulties ${ }^{30}$. Impaired functioning in all categories of occupation, specifically work and social participation with reported subjective lack of social support and unhealthy social situations ${ }^{32}$ are likely to result in relapse of MHCU's with MDD within 6 to 12 months ${ }^{33}$. This is due to the re-establishing of social contacts being problematic and social isolation after discharge contributing to a relapse ${ }^{34}$. These factors all add to the difficulties MHCUs experience in the immediate period after discharge,

In addition, various other challenges including re-adapting to everyday activities in the home, finding the right medication and financial management have been reported. Structuring their time and day has been found to be particularly challenging. Nolan et al. ${ }^{34}$ reported that although participants acknowledged that participation in hobbies, voluntary work or church activities would be beneficial for their recovery, they lacked the confidence and initiative to take the first step to engage in these activities.

Despite the above, there is still limited information on the challenges experienced by South African MHCUs with MDD impacting their functional recovery during and post discharge. This study therefore aimed to explore the challenges that MHCUs considered as contributing to their re-admission to a private acute care hospital within a six-month period.

\section{METHODS}

A social constructionist worldview was used within a descriptive qualitative design ${ }^{35}$. Both systematic and sequential purposive sampling $^{36}$ was used, which implies that the sample size was not set at the onset of the study, but that MHCUs who met the inclusion criteria were invited to participate until the data were saturated. Data saturation was reached after II interviews, as no new information emerged. 
*The Faculty of Health Science of the University of the Witwatersrand approved the research and ethical clearance was obtained from the Human Research Ethics Committee (M06 I007). Permission to conduct the research was obtained from the hospital management. Ethical principles of signed informed consent, voluntary participation and confidentiality were adhered to. The inclusion criteria were adult MHCUs who were fluent in English or Afrikaans, diagnosed with MDD and a first readmission to the research site within a six-month period.

Semi-structured one-on-one interviews were conducted to provide participants with the opportunity to share their experience and perceptions. The interviews were conducted by the researcher in a private room and lasted between 45 minutes to one hour. The researcher had a set of predetermined open-ended questions that served as a guide for the interviews. Prompting was used when necessary, to ensure a clear understanding of what was reported. The following trustworthiness strategies were employed in this study ${ }^{37}$ : Bracketing by means of a written reflection by the researcher was used to understand the researcher's biases about the phenomenon ${ }^{38}$ and understand the participant accounts with an open mind ${ }^{39}$. Due to having experienced challenges post-discharge, participants were able to provide thick, rich data which contributed to the authenticity of the study as it allowed for different participant opinions to be heard. In addition, thick descriptions provided an audit trail of the research to contribute to confirmability of the methodology.

The audiotapes of all interviews were professionally transcribed verbatim. All transcriptions were checked for accuracy by the researcher. The data were analysed using thematic analysis method described by $\mathrm{Creswe}^{37}$, which draws on the analysis procedures of Colaizz ${ }^{40}$. Firstly, transcripts were read and re-read several times. Significant statements were developed. Each significant statement was regarded as being relevant and equal in worth. The researcher then reflected on the meaning of significant statements or codes. Finally, meaning units were grouped together, resulting in clusters or categories, which allowed for the emergence of themes.

Coding was checked by the researcher by re-reading data and relevant quotes were added to clusters. Codes were also confirmed by the two research supervisors.

\section{FINDINGS}

Eleven participants were included in the study. Eight of the participants were female while three were male. Participants were allocated pseudo-names to ensure confidentiality. Two themes emerged from the data analysis (Table I p58): Theme I: "Inability to fully benefit from the therapeutic programme" focused on the fact that participants felt distracted during their first hospital admission and therefore were unable to fully appreciate the changes they needed to make for their recovery. Theme 2: "Life was not what I expected it to be after discharge" highlighted the realisation by participants that life after discharge was still difficult and engagement in structured daily life continued to present a problem.

\section{Theme I: Inability to fully benefit from the therapeutic programme:}

In this theme, participants described not being able to make the most of their time in hospital for two reasons described in the subthemes. The first sub-theme that emerged was participants preoccupation with early discharge compelled by internal and external pressures which distracted them from their engagement in their recovery process. Participant accounts reflected a sense of urgency for early discharge. They reported experiencing internal pressure as others had to take over their responsibilities and their questioning of the severity of their illness and their need for hospitalisation.

\begin{abstract}
"The guilt feeling because you are here... your work colleagues have to stand in for your work, yes and your husband has to take over all your domestic duties" (Rene).
\end{abstract}

All but one of the participants fulfilled the role of spouse and/or parent and stepping out of these caring roles was experienced as abandoning their loved ones.

"Life goes on and I have to be there, people need me. So sorry, I had to go...." (Marie).

Participants also compared their occupational performance with that of some more acutely ill MHCUs and concluded that they ought to be discharged as they seemed well compared to them.

"You look at the others and they seem a lot more ill than you and you realise 'but I am fine', but actually you are not" (Liezel).

Pressures for early discharge were not only experienced as being internal, but participants reported some external pressures as well. Managed health care, imposed restrictions affecting their length of hospitalisation, was reported as one such external pressure. The time the MHCU spent in hospital was not determined by improvement, but by the number of days that their medical scheme allowed for psychiatric hospitalisation per year.

"My medical aid, they said, yes that it [his benefit] was going to be depleted, so therefore I had to go home" (Oscar).

Uncertainty about the amount of funding that was available was also experienced as a stressor which distracted from the recovery.

\footnotetext{
"They spoke about PMB [prescribed minimum benefits], it made me feel anxious because I didn't know about all these things... So, I was afraid of it, I didn't know what they were talking about and I rather wanted to go home before I received this account" (Rene).
}

In addition, some participants spoke of the external pressure from their family members to be discharged. Participants perceived family members as having limited knowledge about MDD and did not understand the MHCU's need for hospitalisation:

"I have been told every day [by my family] that there is nothing wrong with me, I can just as well go home" (Liezel).

Some participants reported that their family perceived that their [the MHCU] admission to hospital as being on a "holiday" while the family had to struggle to manage tasks at home.

\footnotetext{
"You are on holiday, that is how they see it and they have to go on... I think that is also why I wanted to go home too soon the first time" (Alvene).
}

Feedback from family members about how much they were missed

*Ethical clearance for this study was granted prior to the enactment of the amended POPIA on 202I-07-0I. 
Table I: Themes, sub-themes clusters and meaning units

\begin{tabular}{|c|c|c|c|}
\hline Theme & Sub-themes & Clusters & Meaning units \\
\hline \multirow[t]{6}{*}{$\begin{array}{l}\text { Inability to fully benefit from } \\
\text { the therapeutic programme }\end{array}$} & \multirow[t]{4}{*}{$\begin{array}{l}\text { Internal and external pres- } \\
\text { sures for early discharge }\end{array}$} & $\begin{array}{l}\text { Internal struggle due to neglected } \\
\text { occupational roles }\end{array}$ & $\begin{array}{l}\text { - Family needs are more important } \\
\text { than mine } \\
\text { - I should be there }\end{array}$ \\
\hline & & Comparing yourself to others & $\begin{array}{l}\text { - I am not as sick as others } \\
\text { - I can manage better than others }\end{array}$ \\
\hline & & Effects of managed healthcare & $\begin{array}{l}\text { - Medical aid restricts treatment } \\
\text { - Anxiety about finances }\end{array}$ \\
\hline & & Family pressures & $\begin{array}{l}\text { - Come home, you are not sick } \\
\text { - We struggle without you }\end{array}$ \\
\hline & \multirow[t]{2}{*}{$\begin{array}{l}\text { Readiness to engage with } \\
\text { occupational therapy pro- } \\
\text { gramme }\end{array}$} & $\begin{array}{l}\text { Effects of other treatment and a } \\
\text { strange environment }\end{array}$ & $\begin{array}{l}\text { - Effects of medication } \\
\text { - ECT } \\
\text { - Your first admission is } \\
\text { overwhelming. } \\
\text { - Poor self-efficacy and inability to do } \\
\text { things holds you back }\end{array}$ \\
\hline & & Not aware of my health needs & $\begin{array}{l}\text { - Limited insight } \\
\text { - Responsibility for own recovery }\end{array}$ \\
\hline \multirow[t]{5}{*}{$\begin{array}{l}\text { Life was not what I expected } \\
\text { it to be after discharge }\end{array}$} & $\begin{array}{l}\text { Facing the reality that life has } \\
\text { not changed }\end{array}$ & I expected much more.... & $\begin{array}{l}\text { - Medication is a help but not a cure } \\
\text { - I thought I had changed }\end{array}$ \\
\hline & & $\begin{array}{l}\text { People and situations are still the } \\
\text { same }\end{array}$ & $\begin{array}{l}\text { - I was still treated badly } \\
\text { - Problems remain problems } \\
\text { - Your absence makes things worse }\end{array}$ \\
\hline & & Social participation versus isolation. & $\begin{array}{l}\text { - You feel isolated at home. } \\
\text { - You feel detached and different to } \\
\text { people you feel unworthy of their } \\
\text { interaction }\end{array}$ \\
\hline & \multirow[t]{2}{*}{ You struggle to do things } & Participating in structured activities & $\begin{array}{l}\text { - Activity participation lifts your } \\
\text { mood } \\
\text { - Not making effective use of your } \\
\text { time is demotivating } \\
\text { - Having nothing or too much to do }\end{array}$ \\
\hline & & $\begin{array}{l}\text { Implementing coping skills and deal- } \\
\text { ing with stressors }\end{array}$ & $\begin{array}{l}\text { - Real life is different } \\
\text { - Overwhelmed } \\
\text { - Residual symptoms }\end{array}$ \\
\hline
\end{tabular}

also placed external pressure on participants to be discharged early.

The second sub-theme to emerge was the participants' inability to engage in and fully benefit from the occupational therapy programme due to the side effects of other treatments and their own lack of insight into their problems. Participants reflected that this also contributed to their experience of not being prepared for the transition from hospital to home and the resuming of everyday activities on discharge. Participants reported that their ability to concentrate was impaired by the initiation or changing of anti-depressant medication when they were first admitted. They perceived they needed time to adjust to the newly prescribed medication, which resulted in the experience of side-effects and leaving some participants feeling unwell. In some cases, Electroconvulsive Therapy (ECT) during admission also had a profound influence on the participant's ability to absorb information in the occupational therapy programme.

"Many of us are on medication, many of the guys walk around here like zombies so you can't absorb any information in anyway. I went through shock therapy and though I attended all the sessions, and I didn't know what was going on half of the time. Uhm, I couldn't absorb the session, I couldn't benefit from it" (Elsabe).
Another factor that seemed to prevent participants from making the most of their first admission was that it took time to adapt to a new and unfamiliar hospital environment. Many participants felt emotionally overwhelmed, they were unsure what to expect and how the range of therapy related to their health needs. Although MHCUs were encouraged to attend inpatient occupational therapy group sessions immediately after admission, participants reported that it took a few days before they settled down before they felt ready to participate. They particularly found exposure to other patients unsettling:

"I don't like having people around me, I'm a loner" (Liezel).

Another underlying factor perceived as an initial barrier to participation was a lack of self-efficacy and low self-worth. Participants described how a lack of confidence and fear prevented them from actively engaging in the group sessions, resulting in missed opportunities for meaningful interaction. Therefore, by the time that participants felt confident enough to participate, they had lost valuable treatment time during their admission period, which was two weeks on average. A lack of insight during their first admission and the degree to which responsibility for own recovery was 
needed were other factors that made it difficult for participants to benefit from occupational therapy. Participants indicated they only appreciated the value of group work after their first discharge when they were confronted with demanding situations in their lives outside the hospital. They were then able to identify gaps in their functional recovery and attended therapy sessions which addressed their needs.

"I only do the ones, I wouldn't say that concern me, but those that I feel I need like anxiety and depression and those and the conflict management and those, I did the previous time." (Neels).

Participants reported not understanding their own health needs and the severity of their depression as well as the degree to which their daily occupations were disrupted by the disorder. They expected to be cured and they did not take responsibility for their own recovery. They reported being voluntarily admitted to hospital on the advice of their employer or family members, due to concerns about their mental wellbeing. They perceived that their recovery process was driven medical staff, so an external locus of control was evident during the first admission. During the second admission the participants reflected on the process of developing insight and the move from purely adhering to expectations of others to acknowledging the need to take responsibility:

"It was an issue of all the expectations during the first time... it was the best place to go to, do you understand, because you don't cope and you are in a bad state... I was alone with the second time, I had myself admitted and I was determined to walk out of here (Elsabe)

\section{Theme 2: Life was not what I expected it to be after dis- charge:}

Participants reported that they expected their life situation to be different on discharge. Returning to the same situation as before admission was a reality check and presented challenges that made implementing newly acquired skills more difficult than expected. These challenges were intensified by the presence of residual symptoms of depression and remerging occupational dysfunction.

Participants reported they left the hospital with a strong conviction that they had completely recovered and assumed that the negative thought patterns had changed, newly learnt skills had been internalised and that their improved mood state would remain. However, they were challenged when faced with the reality of everyday life. They realised that although the medication reduced the symptoms and enabled more effective coping with situational stressors, the need to implement changes in their engagement in occupations, lifestyle and situation was what was critical to recovery.

"It is not as though your problems are gone. Perhaps the tablets [prescribed medications] help that you are more relaxed about everything, but it is not gone" (Rene).

During hospitalisation, the participants held high expectations for improved functioning in all categories of occupational performance as the depressive symptoms subsided. Participants expressed immense disappointment when it emerged that the positive changes that occurred during occupational therapy sessions could not be implemented at home. This served to retard their recovery and subsequently contributed to their relapse and readmission to hospital.
"It was such a disappointment to me when I realised that I actually was the same Sarie that was admitted" (Sarie).

"... but when I got home, I realised that I was far from okay" (Elna). Participants were taken aback by the realisation that the growth that they had personally experienced was one-sided and people in the outside world did not automatically change. The lack of change in their relationships was perceived as a challenge. Although the participants felt more competent to deal with daily interpersonal struggles using the skills they had acquired during therapy sessions, they held an unrealistic expectation that friends, family members and co-workers had changed the way they related to them:

"[In therapy] we tried to work on how to deal with conflict and stress and everything else. But what awaits you outside, the people that are usually there, I mean nothing about them has changed" (Marie).

Being treated unkindly by significant others was experienced as a major disappointment.

"I expected things to turn out better. That people would treat me better. That my mom would not refer to me as the black sheep any longer" (Elna).

In addition to relationship difficulties, participants also reported that situational stressors remained the same. They were still faced with the same ones that they had encountered before admission and participants were surprised by the problems needing to be resolved after discharge:

"I went home and thought 'Oh well, I am OK, I don't have any problems anymore' but it wasn't like that" (Sarie).

Some participants instead of encountering an improved situation after discharge, the opposite held true, as problematic situations were intensified and their absence while hospitalised complicated matters even more than before admission:

"Nothing changed... as a matter of fact; it's a little bit more intense, because you haven't been there" (Stefan).

Most participants reported the overriding experience at home was a desperate sense of isolation, spending prolonged periods on their own at home. They found it difficult to re-connect with or establish new social contacts after discharge.

"You have no one to talk to if you feel a bit down the day, because you're all alone at home" (Oscar).

Even for those participants that returned to work they reported difficulty in relating to other people as a challenge and described feeling socially detached despite being surrounded by others.

“... all of a sudden I just had this feeling that I didn't fit in here, I don't belong here" (Marie).

Although participants valued the confidence-building aspect of social participation in therapy, this was not consolidated, and their new-found confidence was diminished when they were faced with groups of people after discharge. 
"Making social contact with others... that was hard... To go to church, I felt I wasn't good enough" (Andrea);

"[with others I feel] I am an idiot; I am stupid, and I am ugly. I felt so intimidated by everyone there" (Marie).

Participants were also challenged by the absence of meaningful activities in their lives and not making effective use of their time after discharge. The occupational therapy programme provided structured engagement in activities during the admission which provided structure to the day, served as behavioural activation, taught new skills and improved self-confidence. Participants emphasised the therapeutic value of activities and the sense of purposeful doing that was fostered by activity participation which they now associated with their recovery.

"What really helped me a lot last time, we played a lot of volleyball and the volleyball saved me..... it makes it easier to open up and to say that you have a problem" (Stefan).

The absence of participation and decline in activity levels at home were thought to result in a downward spiral of occupational dysfunction. Limited activity participation reduced the opportunity for positive experiences and a sense of accomplishment, which in turn aggravated depressive symptoms:

"I had all this time on my hands, and I just sat on the bed or lay on the couch and that's wrong. I couldn't motivate myself" (Elsabe).

Other participants felt they had too much to do, and this left them feeling drained and unable to fulfil all their responsibilities.

Finally, participants reported a challenge in applying newly acquired coping and problem-solving skills in the context of their personal life situation which resulted in impaired engagement in occupations. They perceived they did not have sufficient practice opportunity to try out their newly learnt skills before they are discharged. The feasibility of using these skills could therefore only be established after discharge when challenging situations occurred and this was more difficult than they thought.

“..., methods and techniques, it's more difficult to apply it than what you hear, and it doesn't always work like that in reality” (Rene).

"Every time that I experience a crisis, I can't think about [what we learnt on] ...how to solve the problem. The first thing that comes to mind is that I feel extremely tired" (Sarie).

Participant accounts reflected feelings of despondence as they tried to apply the strategies that they had decided upon in therapy, but which failed to deliver the desired outcome and they felt overwhelmed when stressors exceeded whatever coping mechanisms they had to hand.

"It feels as though I can't go on some days. I know that there are I I0, I 20 other people who also have to do it, but I just can't cope with it at this moment. I can't cope with anything at this moment" (Marie).

"I just sat on the couch in a heap and cried for the whole night and half of the following day..." (Daphne).
The presence of residual depressive symptoms was another challenge which made it difficult for participants to deal with stressors.

"I wasn't completely over the depression. I struggled to get going, to get over the depression" (EIna).

“...inside me was no motivation; inside me was no desire to do anything” (Elsabe).

\section{DISCUSSION}

Although various clinical variables have been identified relating to the relapse of $M \mathrm{MD}^{12}$, this study suggests that participation in activities of daily life or functional recovery ${ }^{4}$ is impacted by additional challenges experienced by participants in the post-discharge period which in turn, contributed to their relapse and readmission.

Participants reported experiencing feelings of a guilt-associated inability to fulfil responsibilities that pressurised them to ask for early discharge before sufficient treatment gains had been made. They reported an internal struggle relating to neglecting their occupational roles and accompanying responsibilities on the one hand, whilst acknowledging but under-estimating their own need for treatment on the other. Pressure from relatives to be discharged distracted participants from focusing on their own treatment needs which in some cases, resulted in premature discharge. This finding resonated with a study by Skundberg-Kletthagen et al. ${ }^{41}$ which explored the lived experiences of relatives of a MHCU diagnosed with MDD. Participants in the current study acknowledged that their relatives had to compensate for their absence by taking over their roles and responsibilities, contributing to tension within the family ${ }^{42}$.

Another relevant finding in this study was the implementation of managed healthcare which resulted in a short hospital admission, restricted the time available for therapeutic intervention especially occupational therapy. At the private psychiatric hospital at which this research was conducted, only MHCUs who had a medical aid scheme or were able to personally carry the cost of hospitalization were admitted. When the Medical Schemes Act of 1998 was promulgated, certain medical conditions received better benefits by medical schemes. Schizophrenia and Bipolar Mood Disorder were the only two psychiatric conditions recognised on the list of PMBs, therefore excluding MHCUs with a diagnosis of MDD. Thus, if a client was admitted with a diagnosis of MDD, hospitalisation was limited to a maximum of 2 I days per annum or up to I 5 out-patient psychotherapy contacts ${ }^{43}$. Should another admission be required within the same year, the financial burden lies with the MHCUs themselves. In the current study, restrictions imposed through managed healthcare led to some participants being discharged before optimal therapeutic gains had been made ${ }^{43}$. At the time of his study, the average admission period at the hospital was two weeks and therefore participants were only accommodated during the acute stages of their illness. Furthermore, it can be argued that it is impossible for adequate emotional insight to develop and for sustained behavioural change to occur in such a short period of time ${ }^{44}$. A short hospital stay also implies that MHCUs are discharged at the point of symptom improvement, not remission, which studies have shown to be detrimental to recovery ${ }^{45}$. Short length of stay has been identified as a risk factor for early readmission and in cases where this is influenced by external and internal factors, emphasis should be on a discharge plan and appropriate referrals being made at discharge ${ }^{46}$.

Since only MHCUs struggling with severe depressive symptoms that impair their functioning are admitted ${ }^{47}$, participants also reported feeling emotionally overwhelmed by the experience of a 
first psychiatric hospitalisation. This finding was supported by other qualitative studies which reported on the experience of psychiatric hospitalisation as being in an unfamiliar environment with "mad" and seriously ill people, where participants did not know what to expect or what to do. All these factors contributed to participants' feelings of distress ${ }^{48}$. The challenging period prior to admission and severe symptoms also compromise the ability to learn. In line with current literature, the inability to concentrate and retain information associated with $\mathrm{MDD}^{49}$, participants in this study perceived their depressive symptoms as having the most profound influence on their learning process. Despite this, participants were encouraged to start attending occupational therapy group sessions immediately after admission. This was done as a behavioural activation strategy as well as to optimise the relative short hospitalisation. This strategy might be unwise in the view of previous research which has shown that memory is impaired when learning takes place under stressful circumstances ${ }^{50}$. Therefore, it was clear that participants could not benefit optimally from their treatment programme, especially immediately after admission. The question of the timing of group work that involves learning during the acute phases of MDD, has been raised in other studies that found that MHCUs benefitted from reattending thematic groups after discharge from an acute psychiatric hospital, suggesting that they struggled with the cognitive content while acutely unwell ${ }^{51}$. Tanaka et al. ${ }^{52}$ also concluded that although the attendance of groups during the acute phase of MDD contributed to the perception of recovery, these groups had no effect on readmission rates, which questions the efficiency of learning that took place. Compromised executive functions prevent participants from optimally benefitting from group sessions, negatively affecting MHCUs' functional recovery ${ }^{53}$. The cognitive dysfunction associated with MDD can persist long after the acute phase of the illness ${ }^{28}$ and may therefore affect recall and carry-over of information from the hospital to the MHCUs' "real-life" occupational environments ${ }^{54}$.

A lack of insight as well as reluctance to take responsibility for their recovery resulted in the participants' unrealistic expectations regarding recovery. Firstly, awareness of and insight into one's own needs are necessary to identify the kind of help one needs. For participants in this study, the development of insight was limited due to the challenges restricting the benefit participants indicated they were able derive from occupational therapy groupwork. As suggested by Nunstedt et al. ${ }^{55}$ in their study, the participants indicated they only started to understand MDD, and reflect usefully upon their illness and develop a deeper understanding of their situations after discharge. Emotional rather than intellectual insight also develops through real-life experiences coupled with constructive feedback. Participants reported this was not achieved during their first hospitalisation and participants only developed in-depth understanding of their problems after discharge, when they came face-to-face with challenges. This was supported by Nikendei et al. ${ }^{56}$ who found that one of the main advantages of day hospital attendance compared to inpatient treatment was the effective carry-over of learning experiences, which benefit the development of insight. Although accepting the diagnosis of a psychiatric illness is difficult, this acceptance has been shown to contribute to recovery ${ }^{57}$. Acceptance involves a process which includes acknowledging the illness and taking steps to structure one's life accordingly ${ }^{58}$.

Taking responsibility and engaging in an active approach in managing MDD have been found to contribute towards one's recovery ${ }^{59}$.This is consistent with the Recovery Model ${ }^{22}$. The value attached to personal responsibility differed greatly when comparing participants' first admission to their re-admission. It was only dur- ing re-admission, as insight improved, that meaning was attached to personal responsibility and they became more actively engaged in their recovery process by anticipating potential difficulties and putting an action plan in place to address these ${ }^{55}$. Participants had a greater awareness of their own needs on the later admission and could therefore identify more relevant coping strategies. It could be argued that they did not take responsibility for recovery during their first admission as they lacked insight and in essence, did not know what to take responsibility for.

The second factor that participants perceived to have contributed to their relapse and readmission relate to the unrealistic expectations that they held regarding the recovery process, which resulted in a deep sense of disappointment when they relapsed. This was further aggravated by residual or recurring symptoms which prevented participants from living life in the way that they anticipated after discharge $e^{60}$. As recovery from psychiatric disorders is often viewed in terms of symptom reduction and not functional recovery ${ }^{4}$, the participants in this study viewed improvement of depressive symptoms as recovery. They did not appreciate that functional recovery occurs after the remission of symptoms and is ongoing ${ }^{20}$ and they were taken aback, only realising the extent of their support needs after discharge. They felt that they were thrown back into the "real world" prematurely and perceived that they would have benefitted from a more gradual transition from hospital to home; they found it difficult to settle back into their roles and responsibilities after discharge and the realities of their life-situations that awaited them.

The support of family members or friends is crucial in the recovery of depression, but participants in this study did not feel adequately supported after discharge. On the contrary, they felt blamed for being ill, felt judged and rejected by their support network ${ }^{61}$, even when the support network attempted to offer support, which contributed to the lived experience of loneliness after discharge. It should also be acknowledged that significant others may have experienced a challenging time in the period prior to the hospital admission, especially if there has been a suicidal gesture or threat, and thus might have experienced the burden of care even before the diagnosis was made ${ }^{62}$. Therefore, what participants experienced as poor support in the form of pressure to be discharged and being blamed for being ill, might be indicative of their support structures' justifiable unmet needs and resulting emotional difficulties.

Some participants reported that loved ones tried to offer support, but that they did not know how to offer appropriate support. The reasons for others not being able to provide adequate support, could be hypothesised as: the lack of involvement in the treatment process, lack of insight in MDD and feeling burdened and in need of some emotional support themselves. Furthermore, the occupational therapy programme at the research setting did not allow significant others to attend group sessions as suggested by Priestley and McPherson $^{63}$ and relatives were left to develop coping skills without professional input which may have been limited by the lack of insight about MDD as well as their role in the MHCUs' recovery. They had little understanding of the severity of the disorder and encouraged participants to, figuratively speaking, "pull up their socks". Significant others often expected instant and complete recovery at discharge; this left participants feeling burdened by their expectations.

Although emotional support was available to some participants, they described how they withdrew emotionally and struggled to make use of available support. Participants acknowledged that it is difficult to receive support if you do not 'open up', and they were reluctant to share information or their experiences of depression with others as it made them feel exposed and vulnerable. They also 
felt they may have been the cause of their suffering of significant others' suffering, or a burden to them, and consequently, tended to cut themselves off ${ }^{64}$. In addition, well-meant words of support by significant others were sometimes experienced as judgement or being lectured to ${ }^{61}$. This resonated with a study by Nolan et al. ${ }^{34}$ which explored the experience of being discharged from inpatient psychiatric care, participants in this study described being faced with loneliness as a major challenge after discharge. Participants' feelings of isolation after discharge were heightened by the abrupt transition from an acute hospital setting to participants' home environment ${ }^{56}$ with the loss of structured support from hospital staff and services, including occupational therapy even though there was limited opportunity for follow up treatment sessions with their psychologist and psychiatrist. The participants' withdrawal from relationships was echoed in withdrawal from activities compounding the experience of isolation, which left them vulnerable for relapse and readmission ${ }^{65}$.

The reason for non-participation in activities appeared to be due to lack of structure and motivation. Although the occupational therapy programme promoted occupational engagement by scheduling of daily activities and monitoring accomplishment experienced during engagement in activities, consistent with a study by Skarsater et al. ${ }^{66}$. Some participants struggled to take initiative in or implement planning of their lives after discharge. Those participants who did not return to work after discharge did not anticipate the need for structured activity participation after discharge and the need to consciously reduce avoidance. It was only during their second admission that the value of participation in meaningful activities to distract them from rumination and routine was acknowledged, and participants took responsibility for structuring their time effectively ${ }^{67}$.

The prolonged presence of depressive symptoms also hampered activity participation, whether the residual symptoms were present at discharge or re-emerged once at home. In the current study, participants described being taught coping skills but that the application of these skills in "real-life" situations was difficult. Increased sensitive to stressors ${ }^{28}$ and poor problem solving skills were perceived to have contributed to participants' inability to manage situations after discharge. Some participants faced relentless ongoing stress which for some was experienced as greater than before ${ }^{29}$. They returned to abusive or manipulating home environments or family conflicts and reported using emotional and avoidance coping strategies which limiting participation in occupations ${ }^{30}$ which was perceived as a major setback in their recovery process. Thus, strategies to change personal problems were only being applied to a limited extent ${ }^{56}$. Being admitted as an in-patient eliminated the opportunity to reflect on the difficulties that may be encountered at home and made the transition home at the point of discharge more challenging. Participants in the current study reported that they found it difficult to both learn and implement the coping skills while in hospital, which left them feeling ill prepared to deal with stressors making the familiar homeenvironment a place of vulnerability and distress ${ }^{56}$. The challenges that participants experienced in learning and applying new coping skills to their personal situations, highlight the importance of understanding the recovery process and what influences relapse ${ }^{23}$.

\section{CONCLUSION}

It can be concluded that during the acute phase of an episode of MDD, which usually is when someone is admitted to hospital, is not the ideal period for critical learning to take place. Mental Health Care Users are often acutely ill and as such, do not benefit optimally from group intervention. Therefore, hospitalisation should not be seen as a complete treatment process, and the scope of the occupational therapy programme could potentially be broadened to extent to the period beyond discharge. Learning opportunities offered to MHCUs during hospitalisation should be maximised, by synchronising activity requirements with depressive symptom severity. Groups requiring higher cognitive functions should therefore be attended at a later stage in admission, when symptoms have improved to such an extent that effective learning can take place.

Challenges that participants experienced after discharge can partially be explained by the contrast between their expectations of recovery and the principles of the Recovery model. Participants struggled to regain control of their life situations after discharge. They lacked adequate insight, learning ability was compromised, did not employ active self-management strategies and were faced with disappointment due to unrealistic expectations. These negative experiences were perceived to have contributed to their relapse and readmission to hospital. The introduction of outpatient post discharge support groups needs to be investigated.

\section{AUTHOR CONTRIBUTIONS}

Patricia de Witt was a supervisor of the research study and the main author of the manuscript, and with Fasloen Adams who co-supervised this study, provided guidance during the analysis and interpretation of the data. Nadia Roestroff-Hambrock conceptualised and conducted the research as a post-graduate student. Denise Franzsen assisted with the conceptualisation and write-up of the manuscript.

\section{REFERENCES}

I. World Health Organization. Depression. WHO, Geneva. Available from:

https://www.who.int/news-room/fact-sheets/detail/depression

2. Tomlinson M, Grimsrud AT, Stein DJ, Williams DR, Myer L. The epidemiology of major depression in South Africa: results from the South African stress and health study. South African Medical Journal = Suid-Afrikaanse Tydskrif vir Geneeskunde. 2009;99(5 Pt 2): 367-373.

https://doi.org/10.1016/j.biotechadv.201 1.08.021.Secreted

3. Hays RD, Wells KB, Sherbourne CD, Rogers WH, Spritzer K. Functioning and well-being outcomes of patients with depression compared with chronic general medical illnesses. RAND Corporation; 1996; Available from:

https://www.rand.org/pubs/reprints/RP387.html

4. Romera I, Perez V, Menchón JM, Delgado-Cohen H, Polavieja P, Gilaberte I. Social and occupational functioning impairment in patients in partial versus complete remission of a major depressive disorder episode. A six-month prospective epidemiological study. European Psychiatry, 2010;25(I): 58-65.

https://doi.org/10.1016/j.eurpsy.2009.02.007

5. Rhebergen D, Beekman ATF, de Graaf R, Nolen WA, Spijker J, Hoogendijk WJ, et al. Trajectories of recovery of social and physical functioning in major depression, dysthymic disorder and double depression: A 3-year follow-up. Journal of Affective Disorders. 2010;124(I-2): I48-156. https://doi.org/10.1016/j.jad.2009.10.029

6. Solomon DA, Leon AC, Endicott J, Mueller TI, Coryell W, Shea MT, et al. Psychosocial impairment and recurrence of major depression. Comprehensive Psychiatry. 2004;45(6): 423-430. https://doi.org/10.1016/j.comppsych.2004.07.002

7. Seemüller F, Meier S, Obermeier M, Musil R, Bauer M, Adli M, et al. Three-Year long-term outcome of 458 naturalistically treated inpatients with major depressive episode: severe relapse rates and risk factors. European Archives of Psychiatry And Clinical Neuroscience. 20।4;264(7): 567-575. https://doi.org//0.1007/s00406-0 I4-0495-7 
8. Saohatse L, de Witt P, van Niekerk M. Experiences and perceptions of Return to Work (RTW) by clients with major depressive disorder in an extended sick leave period. South African Journal of Occupational Therapy. 2019;Saonatse,(I): 36-42.

http://dx.doi.org/I0.17/59/2310-3833/2019/vol49n la6

9. James SL, Abate D, Abate KH, Abay SM, Abbafati C, Abbasi N, et al. Global, regional, and national incidence, prevalence, and years lived with disability for 354 Diseases and Injuries for 195 countries and territories, 1990-2017: A systematic analysis for the Global Burden of Disease Study 2017. The Lancet. 2018;392(10159): 1789-1858. https://doi.org/10.1016/S0140-6736(18)32279-7

10. Kessler RC, Bromet EJ. The epidemiology of depression across cultures. Annual Review of Public Health. 2013;34: 1 19-138. https://doi.org/10.1 146/annurev-publhealth-031912-II4409

I I. Freeman C, Joska J. Dealing with major depression in general practice. South African Family Practice. 2013;55(4): 319-325. https://doi.org/10.1080/20786204.2012.10874216

12. Andersson LM, Schierenbeck I, Strumpher J, Krantz G, Topper K, Backman G, et al. Help-seeking behaviour, barriers to care and experiences of care among persons with depression in Eastern Cape, South Africa. Journal of Affective Disorders. 20I3; I5I(2): 439-448. https://doi.org/S0165-0327(13)00502-8 [pii] /n I0.1016/j. jad.2013.06.022 [doi]

13. Sadock BJ, Sadock VA, Ruiz P. Kaplan and Sadock's Synopsis of Psychiatry Behavioral Sciences/Clinical Psychiatry. Kaplan and Sadock's synopsis of psychiatry: Behavioral Sciences/Clinical Psychiatry (I I th ed.). 2015. p. 356-359.

https://doi.org/10.1017/CBO978I107415324.004

14. Lépine JP, Briley M. The increasing burden of depression. Neuropsychiatric Disease and Treatment. 201 I;7(Suppl.): 3-7. https://doi.org//0.2147/NDT.S19617

15. Kamenov K, Caballero FF, Miret M, Leonardi M, Sainio P, TobiaszAdamczyk B, et al. Which Are the Most Burdensome Functioning Areas in Depression? A Cross-National Study. Frontiers in Psychology. 2016;7: 1342. https://doi.org/10.3389/fpsyg.2016.01342

16. Stander MP, Bergh M, Miller-Janson HE, de Beer JC, Korb FA. Depression in the South African workplace. South African Journal of Psychiatry. 2016. https://doi.org/I0.4102/sajpsychiatry.v22il.8I4

17. American Occupational Therapy Association. Occupational therapy practice framework: Domain and process (4th ed.). American Journal of Occupational Therapy. 2020;74(Suppl. 2): 74I24I 0010. https://doi.org/I0.50 I4/ajot.2020.74S200 I

18. Duncan M, Prowse C. Occupational Therapy with Mood Disorders. In: Crouch R, Alers V (eds.) Occupational Therapy in Psychiatry and Mental Health. 5th ed. London: Wiley Blackwell; 2014.

19. Viinamaki H, Hintikka J, Tolmunen T, Honkalampi K, Haatainen K, Koivumaa-Honkanen $\mathrm{H}$. Partial remission indicates poor functioning and a high level of psychiatric symptoms: A 3-phase 6-year follow-up study on major depression. Nordic Journal of Psychiatry. 2008;62(6): 437-443. https://doi.org/10.1080/0803948080195928।

20. Furukawa TA, Takeuchi H, Hiroe T, Mashiko H, Kamei K, Kitamura $\mathrm{T}$, et al. Symptomatic recovery and social functioning in major depression. Acta Psychiatrica Scandinavica. 200 I; 103(4): 257-26I. https://doi.org/10.1034/j.1600-0447.200I.00140.x

21. Kelly M, Lamont S, Brunero S. An Occuational Perspective of the Recovery Journey in Mental Health. British Journal of Occupational Therapy. 2010;73(3): I29-135. https://doi.org/10.4276/0308022 I $0 \times 12682330090532$

22. Davidson L. Recovery, self management and the expert patient - Changing the culture of mental health from a UK perspective. Journal of Mental Health. 2005. p. 25-35. https://doi.org// 0.1080/09638230500047968

23. Gopinath S, Katon WJ, Russo JE, Ludman EJ. Clinical factors associated with relapse in primary care patients with chronic or recurrent depression. Journal of Affective Disorders. 2007; 10I(I-3): 57-63. https://doi.org/10.1016/j.jad.2006.10.023

24. Stroud CB, Davila J, Moyer A. The Relationship Between Stress and Depression in First Onsets Versus Recurrences: A Meta-Analytic Review. Journal of Abnormal Psychology. 2008;117(I): 206-213. https://doi.org/10.1037/0021-843X.1 17.1.206

25. Post RM. Transduction of psychosocial stress into the neurobiology of recurrent affective disorder. American Journal of Psychiatry. 1992. p. 999-1010. https://doi.org/10.1 I 76/ajp. 149.8 .999

26. Monroe SM, Harkness KL. Life stress, the 'kindling' hypothesis, and the recurrence of depression: Considerations from a life stress perspective. Psychological Review. 2005; I I2(2): 4I7-445. https://doi.org/10.1037/0033-295X.1 12.2.417

27. Lewinsohn PM, Steinmetz JL, Larson DW, Franklin J. Depressionrelated cognitions: Antecedent or consequence? Journal of Abnormal Psychology. 1981;90(3): 213-219.

https://doi.org/I0.1037/002I-843X.90.3.213

28. Mitchell PB, Parker GB, Gladstone GL, Wilhelm K, Austin MP V. Severity of stressful life events in first and subsequent episodes of depression: The relevance of depressive subtype. Journal of Affective Disorders. 2003;73(3): 245-252. https://doi.org/10.1016/S0165-0327(01)00479-7

29. Hammen C. Generation of Stress in the Course of Unipolar Depression. Journal of Abnormal Psychology. 1991;100(4): 555-56।. https://doi.org/10.1037/002I-843X.100.4.555

30. Daremo $\AA$, Kjellberg A, Haglund L. Occupational Performance and Affective Symptoms for Patients with Depression Disorder. Advances in Psychiatry. 20I5;20I5: I-6. https://doi.org/I0.I 155/20I5/438I49

31. Backs-Dermott BJ, Dobson KS, Jones SL. An evaluation of an integrated model of relapse in depression. Journal of Affective Disorders. 2010; I24(I-2): 60-67. https://doi.org/10.1016/j.jad.2009.1I.015

32. Brown GW, Harris TO, Kendrick T, Chatwin J, Craig TKJ, Kelly V, et al. Antidepressants, social adversity and outcome of depression in general practice. Journal of Affective Disorders. 2010;121(3): 239-246. https://doi.org/10.1016/j.jad.2009.06.004

33. Skärsäter I, Langius A, Ågren H, Häggström L, Dencker K. Sense of coherence and social support in relation to recovery in firstepisode patients with major depression: A one-year prospective study. International Journal of Mental Health Nursing. 2005; 14(4): 258-264. https://doi.org/ I0. I I I I/j. I440-0979.2005.00390.x

34. Nolan P, Bradley E, Brimblecombe N. Disengaging from acute inpatient psychiatric care: a description of service users' experiences and views. Journal of Psychiatric and Mental Health Nursing. 20 I I; 18(4): 359-367. https://doi.org//0.1 I I I/j.1365-2850.2010.01675.x

35. Sandelowski M. Whatever happened to qualitative description? Research in Nursing \& Health. 2000;23(4): 334-340.

https://doi.org/10.1002/1098-240x(200008)23:4<334::aidnur9>3.0.co;2-g

36. De Vos AS, Delport CSL, Fouche CB, Strydom H. Research at grass roots : for the social sciences and human services professions. Van Schaik; 2011.547 p.

37. Creswell JW, Miller DL. Determining Validity in Qualitative Inquiry. Theory Into Practice. 2000;39(3): I24-130. https://doi.org/ I0.1207/s I 543042 I tip3903_2

38. Chambers E, Cook S, Thake A, Foster A, Shaw S, Hutten R, et al. International update: I. Psychiatric rehospitalization following hospital discharge. Journal of Affective Disorders. NIH Public Access; 20I I;I I (3): 22-27. https://doi.org/10.II59/000I0I500 
39. Starks H, Trinidad SB. Choose your method: a comparison of phenomenology, discourse analysis, and grounded theory. Qualitative health research. 2007;17(10): 1372-1380.

https://doi.org/10.1 I77/104973230730703।

40. Colaizzi P. Psychological research as a phenomenologist views it. In: Valle RS, King M (eds.) Existential Phenomenological Alternatives for Psychology. New York: Open University Press; 1978.

4I. Skundberg-Kletthagen H, Wangensteen S, Hall-Lord ML, Hedelin B. Relatives of patients with depression: experiences of everyday life. Scandinavian Journal of Caring Sciences. 20 I4;28(3): 564-57I. https:// doi.org/I0.1 I I I/scs. I 2082

42. Ahlström BH, Skärsäter I, Danielson E. Living with major depression: experiences from families' perspectives. Scandinavian Journal of Caring Sciences. 2009;23(2): 309-316. https://doi.org/I0.1 I I I/j. I47 I-67I2.2008.00624.x

43. Smit R. Unipolar Depression. CMScript Issue 6. p. I-3. Available from: https://www.medicalschemes.com/files/CMScript/CMScript6Of2016.pdf

44. He H, Chang Q, Ma Y. The Association of Insight and Change in Insight with Clinical Symptoms in Depressed Inpatients. Shanghai Archives of Psychiatry. 2018. p. II0-118.

https://doi.org/10.11919/j.issn.1002-0829.217149

45. Paykel ES. Partial remission, residual symptoms, and relapse in depression. Dialogues in Clinical Neuroscience. 2008. p. 43I-437. https:// doi.org/10.31887/dcns.2008.10.4/espaykel

46. Donisi V, Tedeschi F, Wahlbeck K, Haaramo P, Amaddeo F. Predischarge factors predicting readmissions of psychiatric patients: $A$ systematic review of the literature. BMC Psychiatry. 2016;16(I): 449. https://doi.org/I0. I I86/s I 2888-016-I I I4-0

47. Boerema AM, Kleiboer A, Beekman ATF, van Zoonen K, Dijkshoorn $\mathrm{H}$, Cuijpers P. Determinants of help-seeking behavior in depression: A cross-sectional study. BMC Psychiatry. 2016;16(I): 78. https://doi.org/I0.1 I86/s I 2888-016-0790-0

48. Stenhouse RC. 'Safe enough in here?': patients' expectations and experiences of feeling safe in an acute psychiatric inpatient ward. Journal of Clinical Nursing. 2013;22(2I-22): 3109-3II9. https://doi.org/10.1 I I I/jocn. I 1 I I

49. Herzallah MM, Moustafa AA, Natsheh JY, Danoun OA, Simon JR, Tayem Yl, et al. Depression impairs learning, whereas the selective serotonin reuptake inhibitor, paroxetine, impairs generalization in patients with major depressive disorder. Journal of Affective Disorders. 20I3;I5I(2): 484-492.

https://doi.org/10.1016/j.jad.2013.06.030

50. Vogel S, Schwabe L. Learning and memory under stress: implications for the classroom. npj/Science of Learning. 2016; I(I): I. https://doi.org/10.1038/npjscilearn.2016.1 I

5I. Cowls J, Hale S. It's the activity that counts: What clients value in psycho-educational groups. Canadian Journal of Occupational Therapy. 2005;72(3): I76-182. https://doi.org/10.1 177/000841740507200305

52. Tanaka S, Ishikawa E, Mochida A, Kawano K, Kobayashi M. Effects of Early-Stage Group Psychoeducation Programme for Patients with Depression. Occupational Therapy International. 20I5;22(4): 195-205. https://doi.org/10.1002/oti. I 397

53. Tursi MFDS, Baes CWW, Camacho FRDB, Tofoli SMDC, Juruena MF. Effectiveness of psychoeducation for depression: A systematic review. Australian and New Zealand Journal of Psychiatry. England; 2013. p. 1019-1031. https://doi.org/10.1 |77/00048674|349|154

54. Gillis I, Wilhelm K, Batchelor J, Burke D. Information processing speed remains low in school teachers a decade after recovery from depression. International Journal of Geriatric Psychiatry. 20 I4;29(I0):
1098-I 100. https://doi.org/10.1002/gps.4162

55. Nunstedt H, Nilsson K, Skärsäter I, Kylén S. Experiences of major depression: Individuals' perspectives on the ability to understand and handle the illness. Issues in Mental Health Nursing. 2012;33(5): 272-279. https://doi.org/10.3109/01612840.201।.653038

56. Nikendei C, Haitz M, Huber J, Ehrenthal JC, Herzog W, Schauenburg $\mathrm{H}$, et al. Day clinic and inpatient psychotherapy of depression (DIP-D): Qualitative results from a randomized controlled study. International Journal of Mental Health Systems. 2016;10(I): I-14. https://doi.org/I0.I I86/s I3033-0I6-0074-6

57. Cunningham K, Wolbert R, Graziano A, Slocum J. Acceptance and Change: The Dialectic of Recovery. Psychiatric Rehabilitation Journal. 2005;29(2): 146-148. https://doi.org/I0.2975/29.2005.146. I48

58. Mizock L, Russinova Z, Millner UC. Acceptance of mental illness: Core components of a multifaceted construct. Psychological Services. 2014; I ( I): 97-104. https://doi.org/10.1037/a0032954

59. van Grieken RA, Kirkenier ACE, Koeter MWJ, Nabitz UW, Schene $\mathrm{AH}$. Patients' perspective on self-management in the recovery from depression. Health Expectations. 2015; 18(5): 1339-1348. https://doi.org/10.1 I I I/hex. 12112

60. Desplenter FA, Laekeman GJ, Simoens SR. Following up patients with depression after hospital discharge: A mixed methods approach. International Journal of Mental Health Systems. 201 I;5(1): 1-10. https://doi.org/10.1 186/1752-4458-5-28

61. Y-Garcia EF, Duberstein P, Paterniti DA, Cipri CS, Kravitz RL, Epstein RM. Feeling labeled, judged, lectured, and rejected by family and friends over depression: Cautionary results for primary care clinicians from a multi-centered, qualitative study. BMC Family Practice. 2012; I3(I): I-9. https://doi.org/I0.1 I86/I47I-2296-13-64

62. Da Silva GDG, Jansen K, Barbosa LP, Branco JDC, Pinheiro RT, Magalhães PVDS, et al. Burden and related factors in caregivers of young adults presenting bipolar and unipolar mood disorder. International Journal of Social Psychiatry. 2014;60(4): 396-402. https://doi.org/10.1 I77/0020764013491740

63. Priestley J, McPherson S. Experiences of adults providing care to a partner or relative with depression: A meta-ethnographic synthesis. Journal of Affective Disorders. 2016. p. 4I-49. https://doi.org/10.1016/j.jad.2015.12.01 I

64. Nyström M, Nyström MES. Patients' experiences of recurrent depression. Issues in Mental Health Nursing. 2007;28(7): 673-690. https://doi.org//0.1080/01612840701416064

65. Mgutshini T. Risk factors for psychiatric re-hospitalization: An exploration. International Journal of Mental Health Nursing. 2010;19(4): 257-267. https://doi.org/10.1 I I I/j. 1447-0349.2009.00664.x

66. Skärsäter I, Baigi A, Haglund L. Functional status and quality of life in patients with first-episode major depression. Journal of Psychiatric and Mental Health Nursing. 2006;13(2): 205-213. https://doi.org/I0.1 I I I/j. I365-2850.2006.00942.x

67. Dimidjian S, Hollon SD, Dobson KS, Schmaling KB, Kohlenberg RJ, Addis ME, et al. Randomized trial of behavioral activation, cognitive therapy, and antidepressant medication in the acute treatment of adults with major depression. Journal of Consulting and Clinical Psychology. 2006;74(4): 658-670.

https://doi.org//0.1037/0022-006X.74.4.658

Corresponding Author:

*Patricia de Witt

Email address: patricia.dewitt@wits.ac.za 